With the increased interest in the contribution of occupational therapists to health promotion, the College of Occupational Therapists (2004a) recommended that pre-registration programmes should prepare graduates for practice that includes health promotion. This study ascertained the views of second-year occupational therapy students about health promotion. Thirty-five (30\%) students responded to a self-report questionnaire and demonstrated positive views about the future relationship between health promotion and occupational therapy. The students thought that health promotion should be included in the education of occupational therapists and did not consider that there had been too much emphasis on health promotion in their own education programme.

\title{
Occupational Therapy Students' Views of Health Promotion
}

\author{
Marjorie Jones-Phipps ${ }^{1}$ and Christine Craik ${ }^{2}$
}

\section{Introduction}

Since the Ottawa Charter (World Health Organisation [WHO] 1986) urged health care professionals to become advocates, enablers and mediators for health, there has been growing international interest in their contribution to health promotion (Scriven 2005). An early advocate was Wilcock (1998), who argued that occupational therapy, with its focus on humans as occupational beings and its belief in the positive effects of occupation on health, had a role at both individual and societal level in health promotion and community development. In Canada, Finlayson and Edwards (1995) suggested that health promotion was the integration and partnership between individuals and communities and that occupational therapy had much to offer. Later, the Canadian Association of Occupational Therapists (1998) proposed that therapists could be effective at primary, secondary and tertiary health promotion. Extending this, Goddard (2005), an Australian therapist writing in the American Journal of Occupational Therapy, suggested that occupational

${ }^{1}$ Kent County Council - Social Services. ${ }^{2}$ Brunel University, Uxbridge.

Corresponding author: Christine Craik, Director of Occupational Therapy, School of Health Sciences and Social Care, Mary Seacole Building, Brunel University, Uxbridge, Middlesex UB8 3PH. Email: christine.craik@brunel.ac.uk

Submitted: 23 March 2008.

Accepted: 24 November 2008.

Key words: Health promotion, education, occupational therapy.

Reference: Jones-Phipps M, Craik C (2008) Occupational therapy students' views of health promotion. British Journal of Occupational Therapy, 71(12), 540-544. therapists could be agents of change; for example, in commercial organisations, in aid programmes in developing countries and in international organisations.

Recognising the impact of the Ottawa Charter (WHO 1986) and subsequent declarations, including the Jakarta Declaration on Health Promotion (WHO 1997), the College of Occupational Therapists (COT) (2002) published a strategy on the interaction of provision in health and social care in order to promote the integration of occupational therapy services in the United Kingdom (UK). The strategy referred to health promotion and the WHO International Classification of Functioning, Disability and Health (ICF) (WHO 2001) and recommended that the profession should support the public health agenda. This was later reinforced in guidance on using the ICF (COT 2004b). In relation to education, the COT (2004a) advocated that pre-registration programmes should prepare graduates for practice that included health promotion.

In response to members, the COT (2008) published guidance on health promotion in occupational therapy, citing Scriven and Atwal's (2004, p425) definition of health promotion as:

an holistic field of overlapping activity at primary, secondary and tertiary levels, encompassing health education, lifestyle and preventative approaches alongside the environmental, legal and fiscal measures designed to advance health.

Furthermore, the COT (2008) cited Scriven and Atwal's (2004) definitions of the levels of health promotion. Thus, primary health promotion aims to enhance the health of the well population though activities like health education; 
secondary health promotion focuses on changing individual and group behaviour that may damage health; and tertiary health promotion aims to prevent the further deterioration of existing conditions.

In examining health promotion in occupational therapy in the UK, Scriven and Atwal (2004) considered that it was normally carried out at secondary and tertiary levels by promoting independence in individuals with long-term medical conditions and disability. They proposed that occupational therapists could become primary health promoters, but that this would involve a change in the focus of pre-registration education and continuing professional development.

Despite the assertions that occupational therapists should promote health through practice, there are few examples in the literature. Eaton's (2002) study of psychoeducation in mental health, Tolley and Atwal's (2003) study of a falls prevention programme for older people and the study by Simpson et al (2005) of interventions in mental health all contain elements of health promotion. However, two studies have explored the views of occupational therapists on health promotion.

Seymour (1999) surveyed 100 occupational therapists working with older people in Wales, achieving a 76\% response rate. The therapists demonstrated interesting contrasts: 62 (82\%) respondents reported that occupational therapists should have a greater role in health promotion but only 5 (7\%) considered it an important element of their work. The most important factors to assist therapists in undertaking health promotion were more staff, more time and more support from managers and doctors. The therapists recommended that health promotion should be part of undergraduate education (Seymour 1999).

Similar results were reported by Flannery and Barry (2003), who surveyed 240 members of the Irish Association of Occupational Therapists on their perceptions of health promotion. They obtained a $66 \%$ response rate and found that there were more barriers to, than opportunities for, involvement in health promotion. Some barriers were staffing levels, a lack of resources, and a lack of knowledge and training availability. The study identified that $19 \%$ of the 158 occupational therapists who responded lacked knowledge of health promotion and that $29.8 \%$ of these therapists felt that it was not a priority in busy departments.

With the emphasis on health promotion in theory but the lack of evidence in practice, the differing views of practitioners and the recommendation from the COT (2004a) that it should be a part of pre-registration education, this study aimed to ascertain the views of students on health promotion. The research question was: what are second-year occupational therapy students' views about health promotion? These students were chosen because health promotion had been integrated into their curriculum from the first year and they had had experience of two practice placements. They had also studied a second-year module that aimed to facilitate understanding of the relationship between occupation, health and wellbeing and had explored and applied theories and concepts of health promotion.

\section{Method}

To meet the study aims, a survey methodology was chosen as a convenient and effective way to collect the data and maintain the anonymity of the students. In the absence of a published instrument, a self-report questionnaire was designed, based on the literature and using a closed question format with a Likert scale that would be quick and easy to complete. Attention was paid to Ballinger and Davey (1998), Oppenheim (2000) and Bryman (2004) in its design in order to minimise the acknowledged limitations of postal questionnaires. The final questionnaire had 13 questions, presented in a random order and ending with an invitation to add additional comments. To ensure the brevity of the questionnaire, examples of health promotion activities were chosen. Thus, falls prevention, skills development and joint protection were used because they are frequently cited in the literature.

Although a pilot study has advantages, it was decided not to conduct one, given the participants' awareness of health promotion and their ability to understand the wording of the questions due to the previous teaching on the subject. This meant that issues of reliability were not addressed, but this limitation was accepted.

Following approval from the University Ethics Committee, information sheets and questionnaires were posted to all 115 full-time second-year occupational therapy students. This was undertaken by someone independent of the study in order to preserve the anonymity of the students and the researchers, one of whom was known to the students. Anonymity and confidentiality were emphasised and the students were assured that the questionnaire was not related to their education programme and that their decision about participation would not influence their education. A stamped addressed envelope was enclosed for the return of the completed questionnaire. The data were analysed using the Statistical Package for Social Sciences (SPSS), Version 11, for Windows.

\section{Results}

Thirty-five usable responses were received from the 115 questionnaires distributed, giving a response rate of 30\%. The results have been reordered into three categories: future role for occupational therapy, consistency of occupational therapy and health promotion, and education about health promotion. Eleven participants added comments and these have been included under the relevant headings.

\section{Future role for occupational therapy}

As illustrated in Table 1, 33 (94\%) students agreed or strongly agreed that it will be essential for health promotion to become influential in occupational therapy. Twenty-eight (80\%) students agreed or strongly agreed that the profession's role will become more consistent with health promotion. The view that the integration of health promotion would change the role of occupational therapy produced a 
Table 1. Opinion of 35 students on the future role for occupational therapy

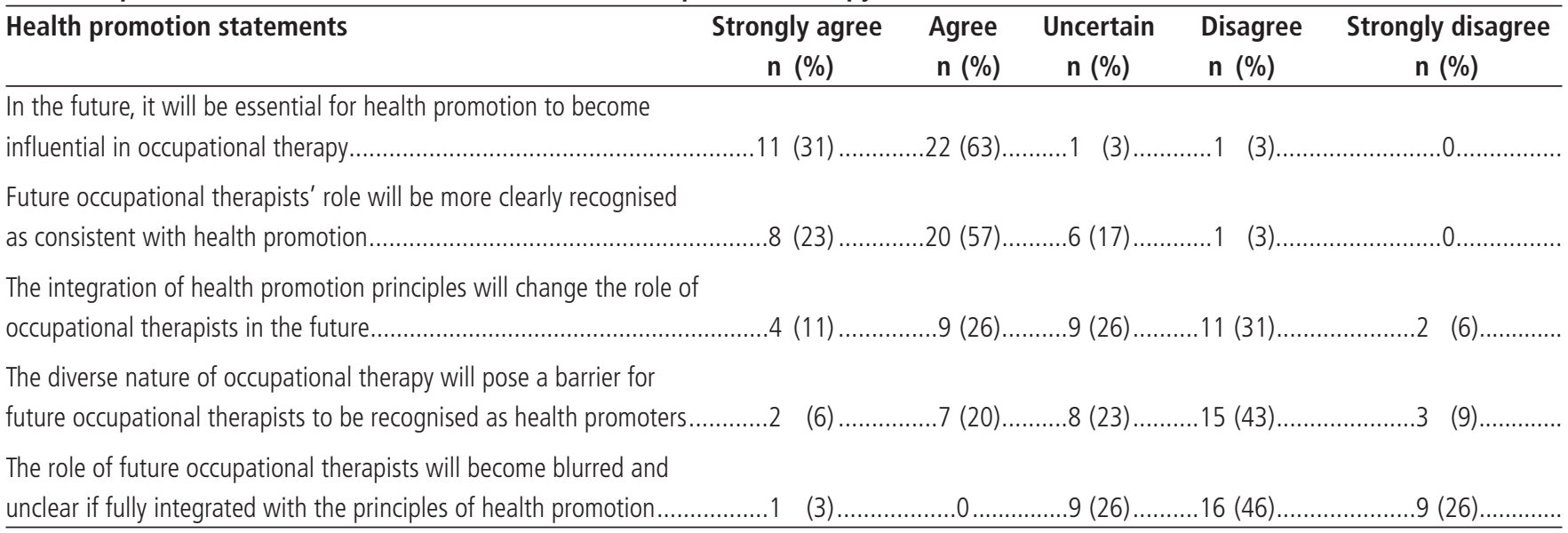

Table 2. Opinion of 35 students on the consistency of occupational therapy and health promotion

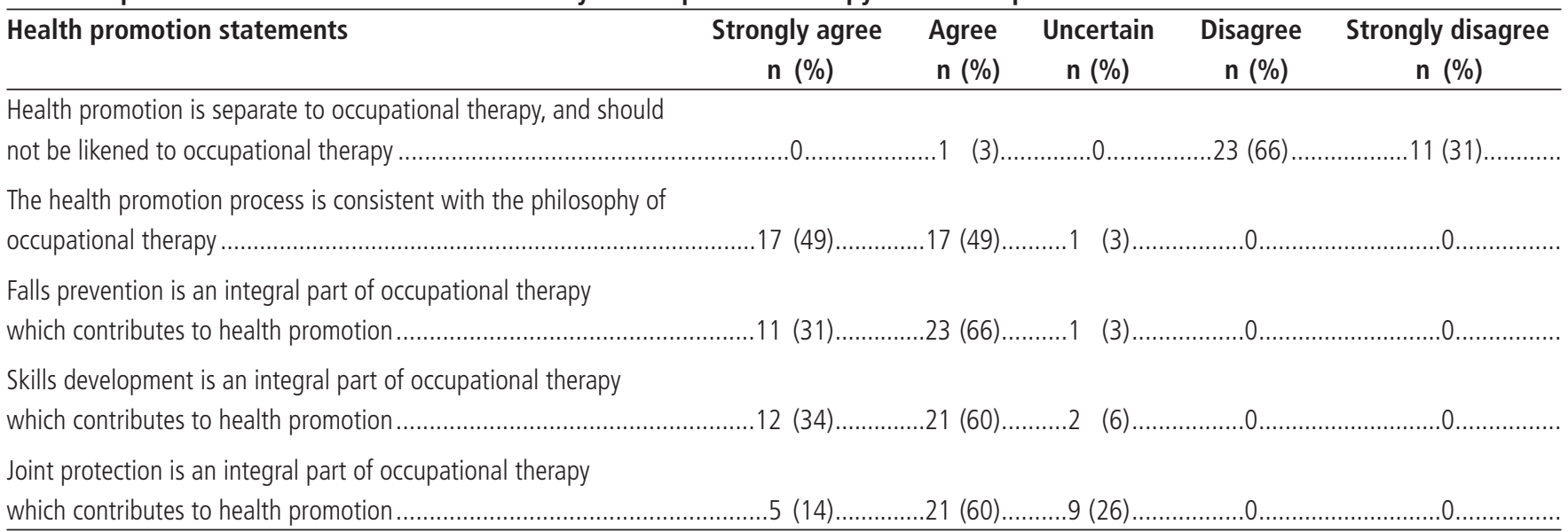

Table 3. Opinion of 35 students on education about health promotion

\begin{tabular}{|c|c|c|c|c|c|}
\hline Health promotion statements & $\begin{array}{l}\text { Strongly agree } \\
\text { n (\%) }\end{array}$ & $\begin{array}{r}\text { Agree } \\
\text { n (\%) }\end{array}$ & $\begin{array}{l}\text { Uncertain } \\
\text { n (\%) }\end{array}$ & $\begin{array}{l}\text { Disagree } \\
\mathrm{n}(\%)\end{array}$ & $\begin{array}{c}\text { Strongly disagree } \\
\mathrm{n}(\%)\end{array}$ \\
\hline 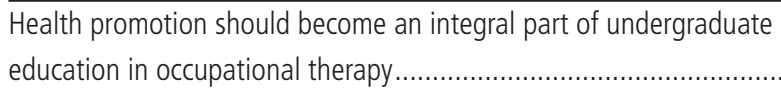 & $.10(29)$.. & $.22(63)$. & $. .2(6) .$. & $. .1(3) .$. &. $.0 \ldots$ \\
\hline $\begin{array}{l}\text { There has been too much emphasis on health promotion on the } \\
\text { undergraduate occupational therapy degree programme ................... }\end{array}$ & $\ldots \ldots 1 \quad$ (3). & $.3(5$ & $4(11)$ & & $\ldots . .6(17) .$. \\
\hline 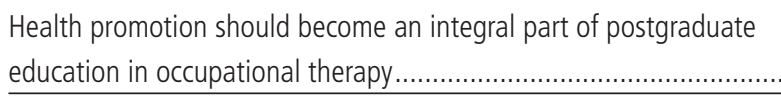 & $\ldots 6(17)$ & $.22(63)$. & $6(17$ & $.1 \quad 13$ & .0 \\
\hline
\end{tabular}

NB. In Tables 1-3, percentages are rounded to the nearest $1 \%$.

balanced response, with broadly similar numbers agreeing, disagreeing and being uncertain.

The students noted that changes in the National Health Service (NHS) would necessitate new ways of working and that health promotion promised some interesting avenues for the profession. More therapists would work with non-governmental organisations in the future, which would incorporate health promotion.

\section{Consistency of occupational therapy and health promotion}

All but one student thought that health promotion was consistent with the philosophy of occupational therapy, as indicated in Table 2. Similarly, all but one or two students considered that falls prevention and skills development, respectively, were integral to occupational therapy and contributed to health promotion. They thought the same of joint protection, but to a lesser extent.

The students commented that the focus of occupational therapy was enabling participation and promoting independence, which contribute to health. The ageing population in the UK will result in health professionals becoming involved in health promotion. However, some students questioned the involvement of occupational therapists and how it could be measured.

\section{Education about health promotion}

Table 3 demonstrates that 32 (92\%) students agreed that health promotion should become an integral part of undergraduate education. This was supported by over 
three-quarters of the students, who disagreed that there was too much emphasis on health promotion in the undergraduate occupational therapy programme. Although $28(80 \%)$ agreed that it should also be part of postgraduate education, one student noted that if health promotion were part of undergraduate education it might not be needed at postgraduate level. Other students commented that health promotion was crucial in occupational therapy and that they were pleased that it had been integrated into their degree in both academic and placement modules

\section{Discussion}

The findings from this study demonstrate that these second-year occupational therapy students had very positive views about the future relationship between health promotion and occupational therapy. They considered that the profession's role would become more consistent with health promotion, but that its identity would not become blurred by the relationship. Thus, they demonstrated similarities to the views of occupational therapists (Seymour 1999, Flannery and Barry 2003) and opinion in the literature. All but two students considered that falls prevention and skills development were integral aspects of occupational therapy and contributed to health promotion. A similar view was held about joint protection, but by fewer students. This may have been due to confusion about the term 'joint protection'. Providing only a few examples of health promotion activities may also have narrowed the focus of the study.

Over $90 \%$ of the 35 students in this study thought that health promotion should be included in occupational therapy education; this supported the findings of Seymour (1999), where $84 \%$ and $77 \%$ of the 76 occupational therapists thought it important or very important to increase the emphasis on health promotion in basic occupational therapy education and postgraduate education respectively. In relation to their own experience, the students disagreed that there had been too much emphasis on health promotion in their educational programme. It would appear that the recommendations of Seymour (1999), COT (2004b) and Scriven and Atwal (2004) have been adopted and that these students identified the health promotion element in their education.

It could be argued that as health promotion has been included in their curriculum, the students would view it favourably. However, occupational therapy students are encouraged to be critical thinkers, are accustomed to evaluating their educational programme and are not reticent in giving their opinions. Indeed, the low response rate to this questionnaire could be related to the frequency with which they are asked for their opinion. In this study, where they had been assured of the anonymity of their responses, there is no reason to doubt their views given through the questionnaire. Nevertheless, other methods of data collection, such as interviews or focus groups, would have allowed more probing of answers and an opportunity to gather richer data. This could be developed in further studies and might also overcome the limitation of a low response rate to questionnaires.

Although previous literature has advocated that occupational therapists have the ability to undertake health promotion, there has been little evidence to demonstrate that the profession has adopted this in practice. Rather, the limited literature on the subject identified barriers to the integration of health promotion as lack of time, lack of funding and staff, lack of support and lack of education resulting in lack of confidence. This study, despite the limitations of its low response rate and restriction to one university, indicates that these students appreciate the value of health promotion and are positive about their future role as occupational therapists using health promotion principles, demonstrating that the subject has already been integrated into the occupational therapy curriculum. Thus, one barrier to adopting health promotion in occupational therapy may have been addressed.

There has been a renewed international call for the building of capacity for health promotion practice (WHO 2006) and for the growth of a competent health promotion workforce, which includes closer links and coalitions with complementary disciplines (International Union of Health Promotion and Education and Canadian Centre for Health Promotion Research 2007, Scriven and Speller 2007). This suggests that the environment is conducive to occupational therapists expanding their role as health promotion practitioners. However, it remains to be seen if occupational therapy students, such as those that took part in this study, will translate their positive views into practice, and form a vital part of this emerging multidisciplinary health promotion workforce. A longitudinal study of these students as they graduate and move into practice would be interesting and might demonstrate different outcomes.

\section{Acknowledgements}

Thanks are extended to the students who participated in the study and to Angela Scriven, Reader in Health Promotion at Brunel University, for her support.

\section{Key findings}

- Occupational therapy students have positive views about the future relationship between health promotion and occupational therapy.

- Occupational therapy students believe that health promotion should be included in occupational therapy education.

- Occupational therapy students have positive views about the inclusion of health promotion in their own education.

\section{What the study has added}

This is the first study to present the views of occupational therapy students on health promotion. It shows that occupational therapy students have positive views on the future relationship between health promotion and occupational therapy. 


\section{References}

Ballinger C, Davey C (1998) Designing a questionnaire: an overview. British Journal of Occupational Therapy, 61(12), 547-50.

Bryman A (2004) Social research methods. 2nd ed. Oxford: Oxford University Press.

Canadian Association of Occupational Therapists (1998) Position Statement on Health Promotion. Canadian Journal of Occupational Therapy, 65(2), 120-21.

College of Occupational Therapists (2002) From Interface to Integration: a strategy for modernising services in local health and social care communities. London: COT.

College of Occupational Therapists (2004a) College of Occupational Therapists: Curriculum framework for pre-registration education. London: COT.

College of Occupational Therapists (2004b) Guidance on the use of the International Classification of Functioning, Disability and Health (ICF) and the Ottawa Charter for Health Promotion in occupational therapy services. London: COT.

College of Occupational Therapists (2008) Health promotion in occupational therapy. London: COT.

Eaton $P$ (2002) Psychoeducation in acute mental health settings: is there a role for occupational therapists? British Journal of Occupational Therapy, 65(7), 321-26.

Finlayson M, Edwards J (1995) Integrating the concepts of health promotion and community into occupational therapy. Canadian Journal of Occupational Therapy, 62, 70-75.

Flannery G, Barry M (2003) An exploration of occupational therapists' perceptions of health promotion. Irish Journal of Occupational Therapy, Winter, 33-41.

Goddard T (2005) Expanding the community role for occupational therapy: becoming political in the corporate sector. American Journal of Occupational Therapy, 59(2), 225-30.
International Union of Health Promotion and Education and Canadian Centre for Health Promotion Research (2007) Shaping the future of health promotion: priorities for action. Paris: IUHPE.

Oppenheim AN (2000) Questionnaire design, interviewing and attitude measurement. London: Continuum.

Scriven A (2005) Health promoting practice: the contribution of nurses and allied health professionals. Basingstoke: Palgrave.

Scriven A, Atwal A (2004) Occupational therapists as primary health promoters: opportunities and barriers. British Journal of Occupational Therapy, 67(10), 424-29.

Scriven A, Speller V (2007) Global issues and challenges beyond Ottawa: the way forward. Promotion and Education, Special Edition Shaping the Future of Health Promotion: Progress and Recommendations, xiv(4).

Seymour S (1999) Occupational therapy and health promotion: a focus on elderly people. British Journal of Occupational Therapy, 62(7), 313-17.

Simpson A, Bowers L, Alexander J, Ridley C, Warren J (2005) Occupational therapy and multidisciplinary working on acute psychiatric wards: the Tompkins Acute Ward Study. British Journal of Occupational Therapy, 68(12), 545-52.

Tolley L, Atwal A (2003) Determining the effectiveness of a falls prevention programme to enhance quality of life: an occupational therapy perspective. British Journal of Occupational Therapy, 66(6), 269-76.

Wilcock AA (1998) An occupational perspective of health. Thorofare, NJ: Slack.

World Health Organisation (1986) Ottawa Charter for Health Promotion. Geneva:WHO.

World Health Organisation (1997) The Jakarta Declaration on Leading Health Promotion into the 21st Century. Geneva: WHO.

World Health Organisation (2001) International Classification of Functioning, Disability and Health. Geneva: WHO.

World Health Organisation (2006) Bangkok Charter for Health Promotion in a Globalized World. Geneva: WHO. 